\title{
Removal of Pb (II) from Synthetic Solution and Paint Industry Wastewater Using Activated Carbon Derived from African Arrowroot (Canna indica) Stem
}

\author{
Takele Sime Tessema $\mathbb{D}^{\mathbb{D}},{ }^{1,2}$ Amare Tiruneh Adugna $\mathbb{D}^{1},{ }^{1,2}$ and M. Kamaraj $\mathbb{D}^{2,3}$ \\ ${ }^{1}$ Department of Environmental Engineering, College of Biological and Chemical Engineering, \\ Addis Ababa Science and Technology University, Addis Ababa 16417, Ethiopia \\ ${ }^{2}$ Bioprocess and Biotechnology Center of Excellence, Addis Ababa Science and Technology University, \\ Addis Ababa 16417, Ethiopia \\ ${ }^{3}$ Department of Biotechnology, College of Biological and Chemical Engineering, Addis Ababa Science and Technology University, \\ Addis Ababa 16417, Ethiopia
}

Correspondence should be addressed to Amare Tiruneh Adugna; amardugna@yahoo.com

Received 6 September 2020; Revised 25 November 2020; Accepted 10 December 2020; Published 19 December 2020

Academic Editor: Shuai Cao

Copyright (c) 2020 Takele Sime Tessema et al. This is an open access article distributed under the Creative Commons Attribution License, which permits unrestricted use, distribution, and reproduction in any medium, provided the original work is properly cited.

\begin{abstract}
This study aimed to investigate the potential of Canna indica stem-based activated carbon (CISAC) for the removal of $\mathrm{Pb}$ (II) ions from synthetic solution and paint industry wastewater. The effects of $\mathrm{pH}$, initial $\mathrm{Pb}$ (II) ion concentration, and adsorbent dose were studied using an aqueous solution prepared using pure lead nitrate $\left(\mathrm{Pb}\left(\mathrm{NO}_{3}\right)_{2}\right)$ on a batch mode. Dried Canna indica stem (CIS) was carbonized in a rectangular furnace at $500^{\circ} \mathrm{C}$ for $2 \mathrm{~h}$ and treated with phosphoric acid $\left(\mathrm{H}_{3} \mathrm{PO}_{4}\right)$ at a ratio of $1: 1$ (w/v). Results showed that the CISAC had $5.4 \%$ of moisture, $5.0 \%$ of ash, $26.7 \%$ of volatile matter, $62.9 \%$ of fixed carbon, and $797.5 \mathrm{mg} / \mathrm{g}$ of iodine number. The Fourier Transform Infrared (FTIR) results showed that the hydroxyl, carboxyl, and phenolic functional groups were dominant in the CISAC surface. Physicochemical characteristics revealed that raw wastewater had a concentration of $4.6 \mathrm{mg} / \mathrm{L} \mathrm{Pb}$ (II), $3 \mathrm{mg} / \mathrm{L} \mathrm{Cu}$ (II), $171 \mathrm{mg} / \mathrm{L} \mathrm{BOD}_{5}, 2402 \mathrm{mg} / \mathrm{L} \mathrm{COD}$, and $619 \mathrm{mg} / \mathrm{L}$ TSS. Better removal of Pb (II) ion from aqueous solution was achieved at a $\mathrm{pH}$ of 5.5 , initial $\mathrm{Pb}$ (II) concentration of $102.4 \mathrm{mg} / \mathrm{L}$, and an adsorbent dose of $1.4 \mathrm{~g}$ using response surface methodology. The highest removal efficiencies of $\mathrm{Pb}$ (II) which was achieved from aqueous solution and paint wastewater were $98 \%$ and $70 \%$, respectively. The experimental data are fitted with Langmuir and Freundlich isothermic models. The results suggested CISAC as a promising adsorbent to remove $\mathrm{Pb}$ (II) ion from paint industry wastewater.
\end{abstract}

\section{Introduction}

Water and land contamination by heavy metals discharged from industrial wastes has become a global problem during the current years [1]. The rapid development of various industrial activities and technologies discharged heavy metals into the environment which highly affected the environment and human health due to their toxicity, bioaccumulation, and bioaugmentation in the food chain and persistence in nature [2]. Heavy metals like arsenic, chromium, copper, mercury, nickel, and silver are among the most widely known toxins found in modern effluents [3].
However, lead is a substantial heavy metal found in wastewater from the paint industry which is toxic to life, even at low concentrations, and can affect the nervous and reproductive system $[3,4]$. To remove heavy metals from industrial effluent, precipitation, ion exchange, coagulation, electrodialysis, etc. are the most commonly used technologies [5]. These technologies have numerous disadvantages such as incomplete metal ion removal, high energy and reagent costs, and toxic sludge [6]. However, adsorption techniques look to be more attractive due to their simplicity, ease of use, high efficiency, and being economical in the removal of heavy metals from wastewater [7]. 
Commercial activated carbon is the most commonly used adsorbent but not cost-effective [8]. Therefore, many researchers were prompted to search for low cost and equally workable adsorbents. Conversion of lignocellulose content to activated carbon is a possible and feasible approach [1]. Some previous studies have reported the production of activated carbon from agricultural residues and other materials for removing $\mathrm{Pb}$ (II) ions from wastewater, for instance, Banana steam [9], Apricot stone [10], Almond shell [11], winemaking waste [12], and pine cone [13]. However, the Canna indica found in Ethiopia (which is planted to decorate homes and public parks) is not yet studied for its potential as an adsorbent. This research investigated the potential of Canna indica stem activated carbon to determine its $\mathrm{Pb}$ (II) ion adsorption capacity from aqueous solution and paint wastewater.

\section{Materials and Methods}

2.1. Preparation of the Adsorbent. The experiment was conducted in an environmental engineering laboratory at Addis Ababa Science and Technology University. The Canna indica stems were collected from the locally available canna indica garden in Addis Ababa city, Ethiopia. Then, the stems were reduced from 1.5 to $3 \mathrm{~cm}$ using a knife and sun-dried for 5 days. The dirt was removed by washing with distilled water and dried in an oven at $105^{\circ} \mathrm{C}$ for $24 \mathrm{~h}$. Then, it was ground using pestle and mortar, and a $100 \mathrm{~g}$ sample was taken and mixed with $100 \mathrm{ml}$ of concentrated phosphoric acid $(85 \% \mathrm{w} / \mathrm{w})$ for $12 \mathrm{~h}$. After that, it was dried in an oven at $105^{\circ} \mathrm{C}$ for $24 \mathrm{~h}$ and carbonized using a rectangular electrical muffle furnace (Nabertherm F 330) at $500^{\circ} \mathrm{C}$ with a heating rate of $25^{\circ} \mathrm{C} / \mathrm{min}$ for $1 \mathrm{~h}$ [14]. The carbonized sample was then taken out of the furnace and cooled in a desiccator and continuously washed with distilled water until a neutral solution was achieved. Finally, it was dried in an oven at $105^{\circ} \mathrm{C}$ for $24 \mathrm{~h}$, ground and sieved using $125 \mu \mathrm{m}$ sieve, and stored in plastic bottles for further use.

2.2. Characterization of the Adsorbent. The proximate analysis (moisture, volatile matter, ash, and fixed carbon content) and iodine number were determined with ASTM (D 2866-2869) and (D4607-94) method, respectively. The functional groups on the prepared adsorbent were determined using a Fourier Transform Infrared (Shimadzu IRAffinity-1s) spectrometer in the spectral range of $4000-400 \mathrm{~cm}^{-1}$ and the data were analyzed by using standard software (Origin 2018 Version 9.55). The X-ray diffraction analysis was also determined using X-ray diffraction (Rigaku Miniflex 600 diffractometer). The XRD was operated at $\mathrm{Cu} \mathrm{Ka}, 40 \mathrm{kV} / 40 \mathrm{~mA}$, and a current of $15 \mathrm{~mA}$. The $\mathrm{X}$-ray diffraction patterns were collected with a scan rate of $4.2^{\circ} \mathrm{C} / \mathrm{min}$ and the results were analyzed using standard software (Origin 2018 Version 9.55).

2.3. Preparation of Aqueous Solution. The lead (II) stock solution $(1000 \mathrm{mg} / \mathrm{L})$ was prepared by dissolving $1.5985 \mathrm{~g}$ of $\mathrm{Pb}\left(\mathrm{NO}_{3}\right)_{2}(99.8 \%)$ with $1000 \mathrm{ml}$ distilled water. The lead standard working solution was prepared by using the following equation:

$$
\mathrm{C}_{1} \mathrm{~V}_{1}=\mathrm{C}_{2} \mathrm{C}_{2}
$$

where $C_{1}$ is the initial concentration, $C_{2}$ is the final concentration, $V_{1}$ is the initial volume, and $V_{2}$ is the final volume

2.4. Collection and Processing of the Paint Industry Effluent. Polythene bottle $(1500 \mathrm{ml})$ was washed with tap water, thoroughly cleaned with hydrochloric acid, and resined with distilled water to make it acid-free, being used to collect the samples. The effluent samples were collected from the paint industry in Addis Ababa (the subcity of Nefas Silk Lafto (latitude: $8^{\circ} 58^{\prime} 50.29^{\prime \prime}$, longitude: $\left.38^{\circ} 44^{\prime} 57.6^{\prime \prime}\right)$ ). The effluent was taken in the morning and afternoon for three days during the first week of July, as there was no further treatment. The sample was immediately transported to the laboratory allowed to settle the solids for $1 \mathrm{~h}$ and analyzed within $24 \mathrm{~h}$. The heavy metals (Pb (II), Cu (II)) and physicochemical characteristics $\left(\mathrm{BOD}_{5}, \mathrm{COD}, \mathrm{TSS}\right.$, turbidity, $\mathrm{pH}$, and temperature) of the effluent before and after adsorption were characterized using the APHA (2010) method.

2.5. Experimental Methods. The experiments were done to optimize the influence of experimental factors such as $\mathrm{pH}$ (3, 5.5, and 8$)$, adsorbent dose $(0.5,1$, and $1.5 \mathrm{~g})$, and initial concentration of $\mathrm{Pb}$ (II) ions $(50,100$, and $150 \mathrm{mg} /$ $\mathrm{L})$ for the removal efficiency of $\mathrm{Pb}$ (II) ion from aqueous solution. Using the optimal experimental conditions, the real paint industry wastewater was examined for the removal efficiency of $\mathrm{Pb}$ (II) ion. The experiments were conducted in a $250 \mathrm{ml}$ Erlenmeyer flask with a constant speed of $250 \mathrm{rpm}$ and a contact time of $120 \mathrm{~min}$ at room temperature [15] on a batch basis. Then, it was filtered using $0.45 \mu \mathrm{m}$ Whatman filter paper to separate from the adsorbent. The residual $\mathrm{Pb}$ (II) ion concentration was determined by using Microwave Plasma Atomic Emission Spectrometry (Agilent mp-aes 4200). All of the experiments were performed in triplicate. The removal efficiency and adsorption capacity qe $(\mathrm{mg} / \mathrm{g})$ were calculated using the following equations, respectively:

$$
\begin{aligned}
\mathrm{R} & =\frac{\mathrm{C}_{\mathrm{o}}-\mathrm{C}_{\mathrm{e}}}{\mathrm{C}_{\mathrm{o}}} * 100, \\
q_{e} & =\left(\mathrm{C}_{\mathrm{o}}-\mathrm{C}_{\mathrm{e}}\right) \frac{v}{m},
\end{aligned}
$$

where $C_{\mathrm{o}}$ and $C_{\mathrm{e}}$ are the initial and the final $\mathrm{Pb}$ (II) ion concentration $(\mathrm{mg} / \mathrm{L})$, respectively, $V$ is the adsorbate volume (L), and $m$ is the mass of adsorbent $(\mathrm{g})$.

2.6. Experiment Design and Optimization. The experimental design for process optimization and its statistical analysis was carried out using Design Expert ${ }^{\circledR}$ software version 7.0.0. The relationship between dependent response variables and a set of quantitative experimental factors (independent 
variables) was analyzed by using the Box-Behnken factorial surface ( 3 levels and 3 factors). This design was utilized to determine the effect of three factors initial $\mathrm{Pb}$ (II) ion concentration, adsorbent dosage, and $\mathrm{pH}$ on the removal efficiency of $\mathrm{Pb}$ (II) ion using Canna indica-activated carbon over three levels. The ranges and levels of the experimental parameters are shown in Table 1.

The total number of experiments was determined using the following equation:

$$
\mathrm{N}=2^{\mathrm{F}}+2 \mathrm{~F}+\mathrm{x}_{o}
$$

where $\mathrm{N}$ is the number of experimental runs, $\mathrm{F}$ represents the factor number, and $x_{\mathrm{o}}$ is the number of replicates at the central point. In this study, the values of $\mathrm{N}, \mathrm{F}$, and xo were 17, 3, and 5, respectively. The relationship between coded and actual values of variables was measured using the following equation:

$$
x_{i}=x_{i}=\frac{X_{i}-X_{o}}{\Delta x},
$$

where $x_{i}$ is the dimensionless coded value of the $\mathrm{i}^{\text {th }}$ independent variable, $X_{o}$ is the value of $X_{i}$ at the center point, and $\Delta x$ is the step change value. A second-order polynomial response surface model for the fitting of experimental data was calculated using the following equation:

$$
\left.y=b_{o}+\sum_{i}^{n} b i x i+\sum_{i}^{n} b i i x^{2} i\right)+\sum_{i}^{n} b_{i j} x_{i X_{j}},
$$

where $y, x_{\mathrm{i}}, b_{\mathrm{o}}$, and $b_{\mathrm{i}}$ represent the predicted response, independent variables, constant offset term, and linear coefficients, respectively. Furthermore, $b_{i i}$ represents the regression coefficients for the quadratic and $b_{i j}$ represents interaction effects.

2.7. Adsorption Isotherms. Langmuir and Freundlich isotherm models were used in this work: the Langmuir isotherm theory assumes monolayer adsorbent distribution over a homogeneous adsorbent surface. The Langmuir isotherm is presented in the following equation:

$$
\frac{C e}{q e}=\frac{C e}{q m}+\frac{1}{K_{L} q m},
$$

where $q_{\mathrm{m}}$ is the maximum amount of metal ion adsorbed capacity $(\mathrm{mg} / \mathrm{g}), q e$ is the amount of metal ion per unit mass of adsorbent at equilibrium $(\mathrm{mg} / \mathrm{g}), K_{\mathrm{L}}$ is a constant related to the binding energy of adsorption, and the other constants can be estimated by plotting $C e$ versus qe.

The Freundlich isotherm is an empirical equation describing heterogeneous surface adsorption. The Freundlich isotherm is commonly presented as shown in the following equation:

$$
q_{e=} k f c e^{1 / n}
$$

where $k_{f}$ is the Freundlich constant related to adsorption capacity $(\mathrm{mg} / \mathrm{g})$ and $n$ is the Freundlich exponent (dimensionless). By taking the logarithmic function of equation (8), it is simplified to the following equation:
TABLE 1: Coded and real values of operational parameters for the Box-Behnken statistical design.

\begin{tabular}{lccc}
\hline \multirow{2}{*}{ Factors } & \multicolumn{3}{c}{ Levels of Box-Behnken } \\
& Low $(-1)$ & Middle $(0)$ & High $(+1)$ \\
\hline $\mathrm{pH}\left(x_{1}\right)$ & 3 & 5.5 & 8 \\
Adsorbent dose $\left(x_{2}\right)$ & 0.5 & 1 & 1.5 \\
Initial concentration $\left(x_{3}\right)$ & 50 & 100 & 150 \\
\hline
\end{tabular}

$$
\log q_{e}=\log k_{f} \frac{1}{n} \log c_{e}
$$

\section{Results and Discussion}

3.1. Proximate and Iodine Number Analysis. The results of proximate and iodine number analysis values are presented in Table 2. In observation of the data of proximate analysis, CISAc shows low ash content (5\%), medium content of volatile matter $(26.7 \%)$, low moisture content $(5.4 \%)$, and a high percentage of fixed carbon (62.9\%). The moisture content value was lower than the values reported by Olugbenga et al. [16] and Ozdemir et al. [36] while studying the activated carbon from Pawpaw (Carica papaya) leaf and grape stalk, respectively. This indicates that CISAC may have better removal potential due to its lower moisture content [17]. However, the volatile matter contents of this were more than the value obtained from Banana (Musa paradisiaca) stalk-based activated carbon [18]. The fixed carbon for CISAC was better than the activated carbons made from Banana empty fruit bunch, Delonix regia fruit pod [19], and pumpkin seed shell [20]. The medium content of volatile matter and the low ash content usually increase the solid yield of the carbon and produce high fixed carbon [21]. Better performance was obtained when there is a high microstructure which is directly correlated with the iodine value. The higher number of carbons in iodine was due to the presence of a large structure of micropores and the high likelihood of carbons having a large surface area due to the enlargement of their pore structure [22]. The iodine value is significantly affected by activation temperature and time (Mopoung et al. [14]) and Kumar et al. [23] reported an activation time of 1 to $2 \mathrm{hr}$, and the activation temperature within 500 to $600^{\circ} \mathrm{C}$ increases the microstructure.

The iodine number of the CISAC was greater than a value obtained from activated carbon from Cassava peels [24] and Lapsi (Choerospondias axillaris) seed stone [25]. This shows that CISAC has a better removal capacity as a higher iodine number of carbons credited to the nearness of large micropore shape and to have expansive surface vicinity due to the broadening of their pore structure [26].

3.2. FTIR Analysis of CISAC. Table 3 presents the FTIR spectral characteristics of CISAC based on $\mathrm{pH}$ (7 and 5.5), initial $\mathrm{Pb}$ (II) ion concentration ( 0 and $50 \mathrm{mg} / \mathrm{L}$ ), and adsorbent dosage (1 and 1.5) before and after $\mathrm{Pb}$ (II) ion adsorption, respectively. The FTIR spectrum of the activated carbon shows a significant difference in peak frequencies due 
TABLE 2: The proximate and iodine number analysis for CISAC.

\begin{tabular}{lc}
\hline Parameters & Value (\%) \\
\hline Moisture & 5.4 \\
Ash & 5.0 \\
Volatile matter & 26.7 \\
Fixed carbon $(\%)$ & 62.9 \\
Iodine number (mg/g) & 797.5 \\
\hline
\end{tabular}

TABLE 3: FTIR spectral characteristics of CISAC before and after $\mathrm{Pb}$ (II) ion adsorption.

\begin{tabular}{lcccc}
\hline $\begin{array}{l}\text { FTIR } \\
\text { peak }\end{array}$ & $\begin{array}{c}\text { Assigned functional } \\
\text { groups }\end{array}$ & \multicolumn{3}{c}{ Band wave number $\left(\mathrm{cm}^{-1}\right)$} \\
\hline 1 & Before & After & $\begin{array}{c}\text { Shift } \\
\text { differences }\end{array}$ \\
2 & $\begin{array}{c}\text { Hydroxyl (O-H) } \\
\text { Methyl and methylene } \\
\text { (C-H) }\end{array}$ & 3450 & 3394 & 56 \\
3 & Methyl and methylene & 2374 & 2368 & 6 \\
4 & $\quad$ (C-H) & 2291 & 0 \\
5 & Acetyl (C=O) & 1620 & 1606 & 14 \\
6 & Carbonyl (CC ) & 1383 & 1320 & 63 \\
7 & Nitrate (NO $)$ & 1313 & 1236 & 77 \\
8 & Aryl (C-O) & 1166 & 1152 & 14 \\
\hline & Aryl (C-O) & 1040 & 398 & 642 \\
\hline
\end{tabular}

to the binding of $\mathrm{Pb}$ (II) ion with active sites of the activated carbon indicating the presence of ionizable functional groups on the activated carbon which has the potential to interact with other cations [4].

The FTIR spectra of CISAC before and after adsorption of $\mathrm{Pb}$ (II) ion are revealed in Figure 1. The recorded spectra give different adsorption peaks which represent the presence of various functional groups in the CISAC. The spectra of CISAC before adsorption of $\mathrm{Pb}$ (II) ion band at $3450 \mathrm{~cm}^{-1}$ representing stretching vibrations of $\mathrm{O}-\mathrm{H}$ in hydroxyl group and band at $2374 \mathrm{~cm}^{-1}$ assigned to $\mathrm{C}-\mathrm{H}$ stretching indicate the methyl and methylene [27]. Besides band at $1620 \mathrm{~cm}^{-1}$ stretching of the acetyl group in hemicellulose, band at $1383 \mathrm{~cm}^{-1}$ indicated stretching in the aromatic ring, band at $1313 \mathrm{~cm}^{-1}$ attributed to $\mathrm{N}-\mathrm{O}$ stretching vibration, and band at $1166 \mathrm{~cm}^{-1}$ and $1040 \mathrm{~cm}^{-1}$ associated with the $\mathrm{C}-\mathrm{O}$ stretching of the aryl group in lignin, respectively [21]. All of the assigned wave numbers of CISAC after adsorption are different from before adsorption except for one of them where many wavenumbers shift during the adsorption process.

3.3. XRD Analysis. X-ray diffraction was used to assess the presence of amorphous and crystalline between the matrixes of carbon. The X-ray powder diffraction spectra are presented in Figure 2. According to the powder diffraction results, the CISAC shows two broad intense peaks at $2 \Theta=23^{\circ}$ and $2 \Theta=24^{\circ}$. These were a sign of crystalline graphite formation inside the carbon [28]. The spectra pattern exhibits a persistent decrease in crest concentration as a result collapse of the graphite layers. This can be an ordinary amorphous carbon arrangement [29].
3.4. Paint Industry Untreated and Treated Wastewater Characteristics. Table 4 presents the untreated and treated wastewater characteristics collected from the paint industry. The concentrations of most parameters for the untreated wastewater, except for $\mathrm{pH}$ and temperature, were above the WHO standard. Particularly, the $\mathrm{Pb}$ (II) ions concentration was 46 times higher than the standard; hence, it must be removed to avoid environmental risks.

The treated wastewater characteristics were below the standard set by WHO (2017) except for COD and TSS. Hence, further treatment is needed to remove the excess COD and TSS before disposing to the environment. Though the research was concentrated on $\mathrm{Pb}$ (II) removal, [30] reported the biochar made from Canna indica has the potential to remove cadmium from an aqueous solution which shows that it might have a potential to remove other heavy metals.

\subsection{Effects of Individual Factors on Pb (II) Ion Removal Efficiency}

3.5.1. Effects of $p H$. The influences of $\mathrm{pH}$ were investigated in the range of 3-8 under constant initial $\mathrm{Pb}$ (II) concentration of $100 \mathrm{mg} / \mathrm{L}$, a contact time of 120 , and an adsorbent dose of $1.5 \mathrm{~g}$. Figure 3 (a) displays the $\mathrm{Pb}$ (II) ions removal efficiency was increased when the solution of $\mathrm{pH}$ increased from 3 to 5.5. The better removal of $\mathrm{Pb}$ (II) ion was achieved at $\mathrm{pH} 5.5$ while the removal decreased under highly acidic and moderate basic conditions. A similar finding was reported by Gundogdu et al. [31]. At a highly acidic pH, the overall surface charge on the active site becomes positive and metal cations and protons compete for the binding site of the adsorbent [32]. The removal efficiency was decreased when the values of $\mathrm{pH}$ increased from 5.5 to 8 . In this condition, $\mathrm{Pb}$ (II) ions were precipitated in the form of $\mathrm{Pb}(\mathrm{OH})_{2}$ [33]. Related trends were reported for the adsorption of $\mathrm{Pb}$ (II) ions on the activated carbon prepared from coconut shell [34].

3.5.2. Effects of Initial Pb (II) Ions Concentration. The better removal was achieved at the initial $\mathrm{Pb}$ (II) ion concentration of $50 \mathrm{mg} / \mathrm{L}$ (Figure 3(b)). The elimination of $\mathrm{Pb}$ (II) ion was decreased with the increase in concentration from 50 to $150 \mathrm{mg} / \mathrm{L}$; because of low concentration, there is a low number of lead ions to the ration of the surface-active site found in the adsorbent surface. Therefore, all of the lead ions may interact with the active site. In contrast when higher initial concentration proved more lead ion for being attached on the adsorbent surface, as a result, the active site is not sufficient and saturation in the adsorbent has happened which resulted in the reduction of removal efficiency.

3.5.3. Effects of Adsorbent Dosage. The effect of an adsorbent dose was investigated by altering the adsorbent in the range of $0.5-1.5 \mathrm{~g} / 100 \mathrm{ml}$. The fixed parameters were $\mathrm{pH}$ of 5.5 , a contact time of $120 \mathrm{~min}$, and an initial $\mathrm{Pb}$ (II) ion concentration of $100 \mathrm{mg} / \mathrm{L}$. Figure 3(c) shows the removal of $\mathrm{Pb}$ (II) ion was increased while the adsorbent dose increased 


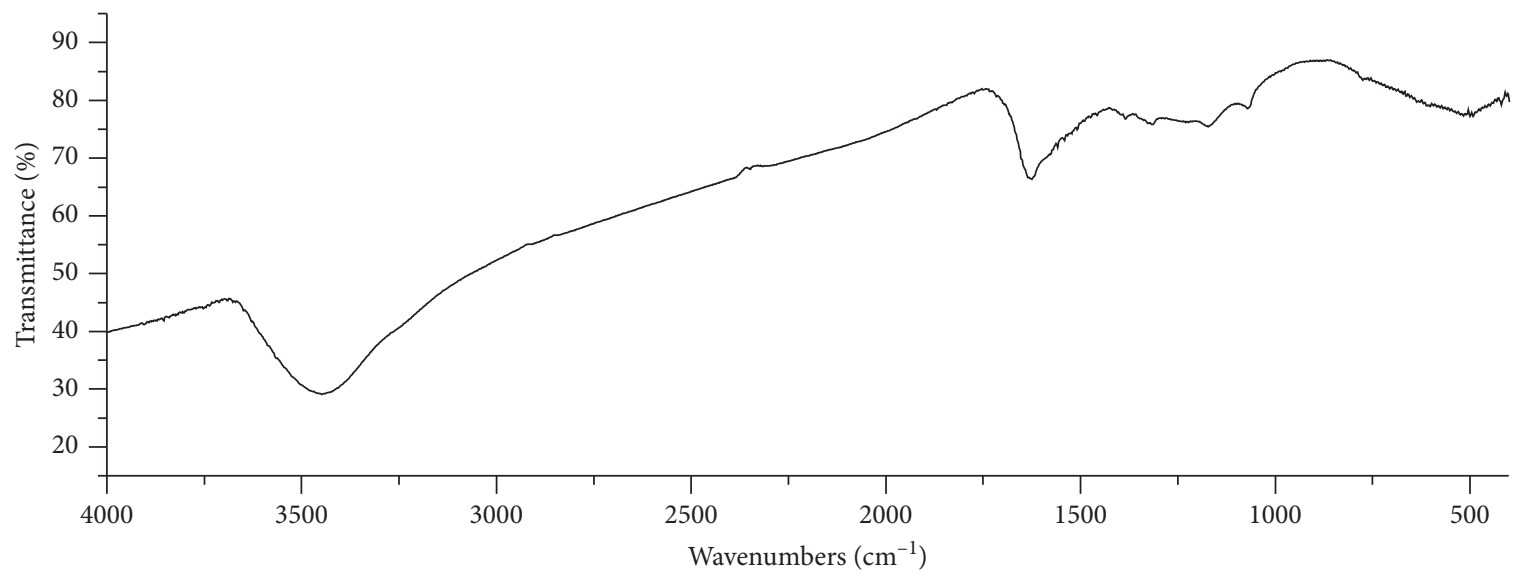

(a)

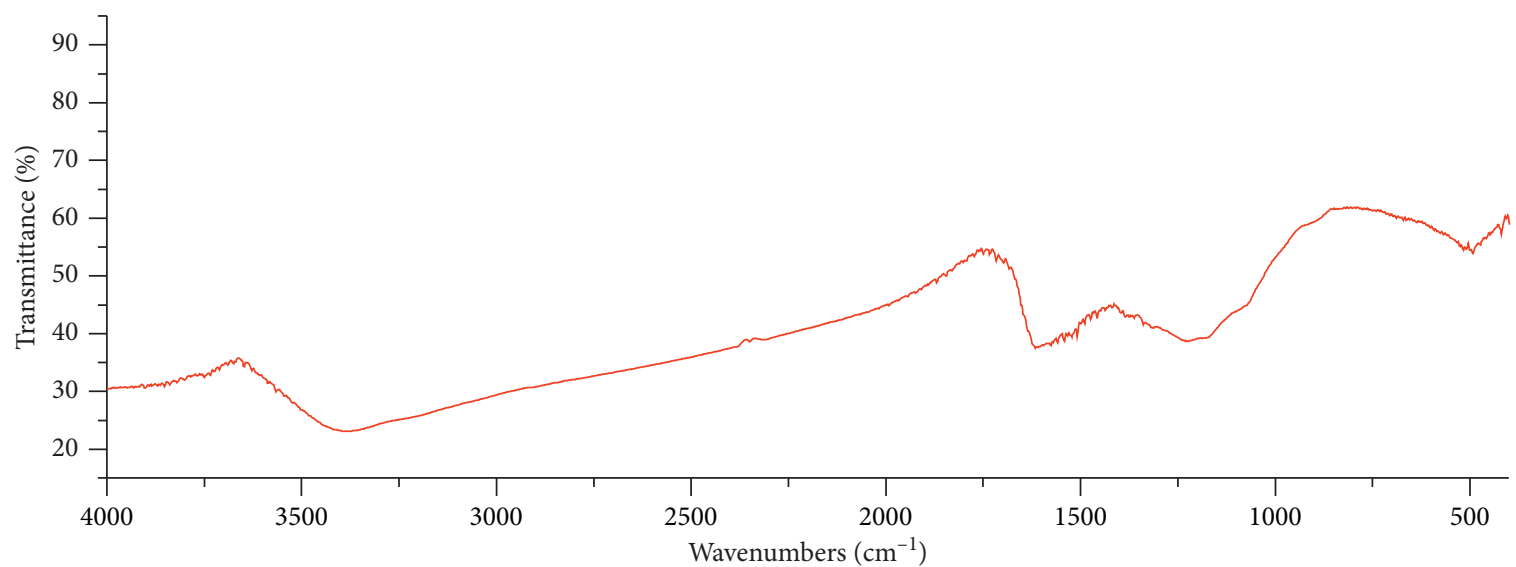

(b)

Figure 1: FTIR analysis of CISAC before (a) and after (b) Pb (II) ion adsorption.

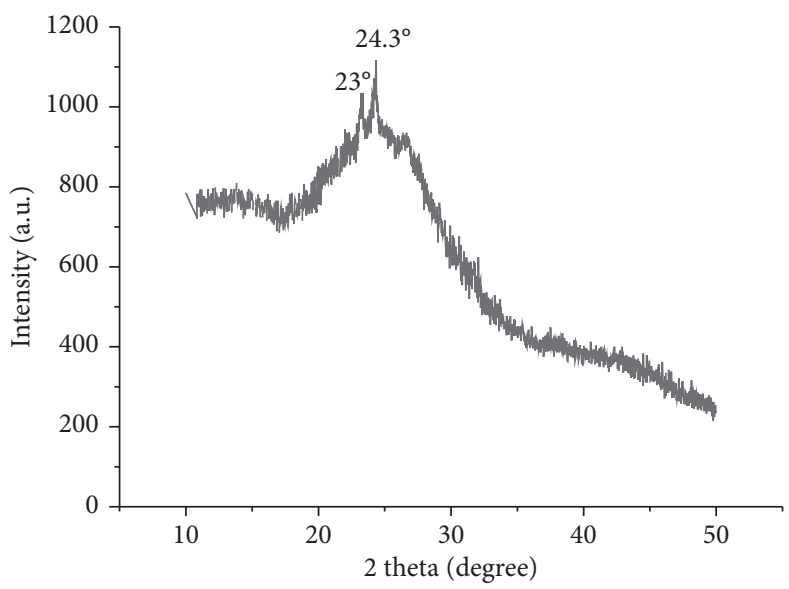

FIgURE 2: XRD analysis of CISAC.

from 0.5 to $1.5 \mathrm{~g}$. It is due to a constant initial concentration whilst growing the adsorbent dose gives a higher adsorption surface area. However, a reverse trend was observed for adsorption capacity. A similar result was reported in the elimination of $\mathrm{Pb}$ (II) ion from aqueous solution using bamboo-based activated carbon as adsorbent [35]. The elimination of lead (II) increased with an increase in the adsorbent dosage and then it remains almost constant which leads to better removal at $1.5 \mathrm{~g}$ of adsorbent.

3.6. Process Optimization and Effects of Factors Interaction Response Surface Methodology. 3D plots can be drawn for a different combination of parameters which show the trend of 
Table 4: Paint industry wastewater (untreated and treated) characteristics.

\begin{tabular}{lcccc}
\hline Parameters & Unit & Untreated wastewater & Treated wastewater & Maximum limited value (WHO, 2017) \\
\hline $\mathrm{pH}$ & $\mathrm{pH}$ unit & 5.3 & 6.5 & $6.5-9.2$ \\
Temperature & ${ }^{\circ} \mathrm{C}$ & 20.6 & 20 & 40 \\
Turbidity & $\mathrm{NUT}$ & 255 & 10 & - \\
$\mathrm{BOD}_{5}$ & $\mathrm{mg} / \mathrm{L}$ & 171 & 25 & 40 \\
$\mathrm{COD}$ & $\mathrm{mg} / \mathrm{L}$ & 2402 & 150 & 120 \\
$\mathrm{TSS}$ & $\mathrm{mg} / \mathrm{L}$ & 4.6 & 138 & 45 \\
$\mathrm{~Pb}(\mathrm{II})$ & $\mathrm{mg} / \mathrm{L}$ & 3 & 0.428 & 0.1 \\
$\mathrm{Cu}(\mathrm{II})$ & $\mathrm{mg} / \mathrm{L}$ & & 0.268 & 1 \\
\hline
\end{tabular}

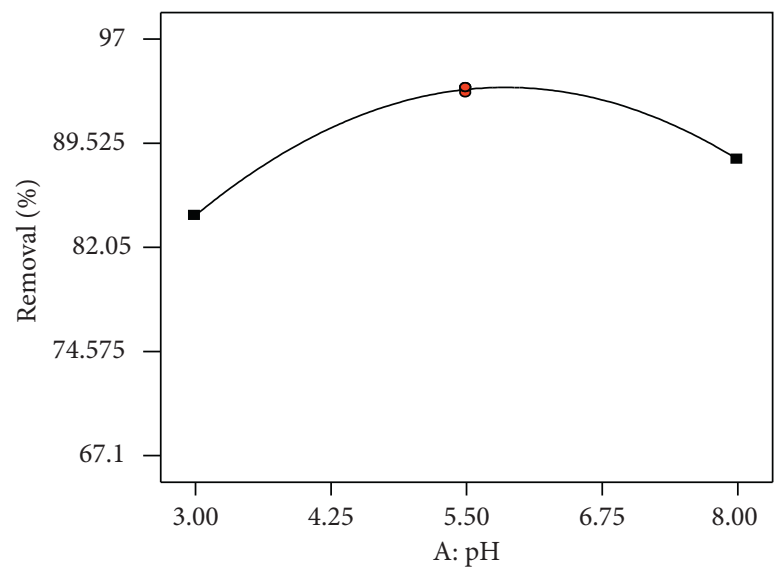

(a)

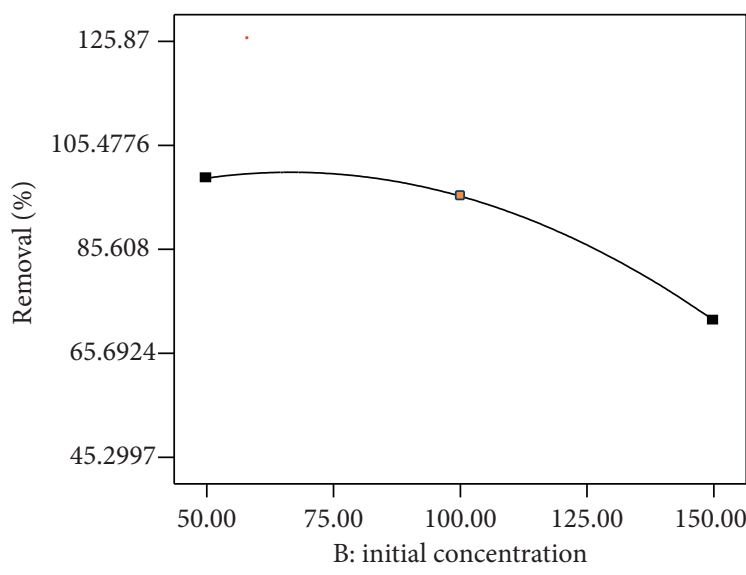

(b)

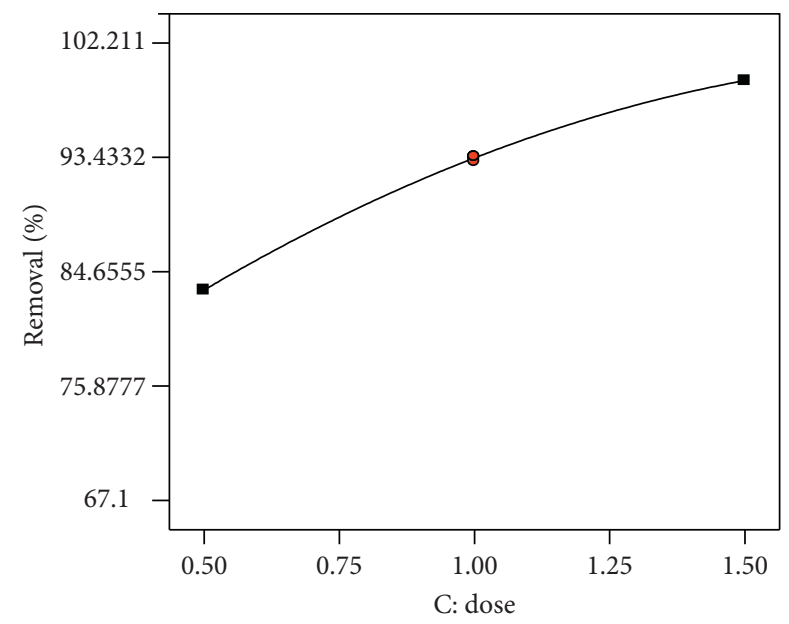

(c)

Figure 3: Individual effects of $\mathrm{pH}$ (a); initial $\mathrm{Pb}$ (II) ions concentration (b); and adsorbent dosage (c) on Pb (II) adsorption by CISAC.

variation of response within the selected range of input factors (( $\mathrm{pH}$, initial $\mathrm{Pb}$ (II) ions concentration, and an adsorbent dose) and the influence of each parameter over the other parameters. Few such typical plots are shown in Figure 4.

Figure 4(a) shows the 3D plot, the combined effects of $\mathrm{pH}\left(x_{1}\right)$, and initial $\mathrm{Pb}$ (II) ion concentration $\left(x_{2}\right)$ on the elimination efficiency of $\mathrm{Pb}$ (II) ion by keeping the adsorbent dose constant. The result from Figure 4(a) indicates that the elimination efficiency was increased with an increase in the solution of $\mathrm{pH}$ from 3 to 5.5 with decreasing the $\mathrm{Pb}$ (II) ion concentration from 150 to $50 \mathrm{mg} / \mathrm{L}$ and then decreased when further increasing $\mathrm{pH}$ from 5.5 to 8 .
The 3D surface plot in Figure 4(b) displays the $\mathrm{Pb}$ (II) ion removal efficiency as the combined effects of adsorbent dose $\left(x_{3}\right)$ and $\mathrm{pH}\left(X_{1}\right)$ in maintaining the initial $\mathrm{Pb}$ (II) ion concentration constant. The removal of $\mathrm{Pb}$ (II) ion decreased when the $\mathrm{pH}$ decreased from 5.5 to 3 with the decrease in the adsorbent dose from 1.5 to $0.5 \mathrm{~g}$. Then, the removal efficiency increased when the $\mathrm{pH}$ decreased from 8 to 5.5 and the adsorbent dose increased from 0.5 to $1.5 \mathrm{~g}$.

The $3 \mathrm{D}$ plot which was constructed to show the most significant two factors of adsorbent dose $\left(X_{3}\right)$ and initial $\mathrm{Pb}$ (II) ion concentration $\left(x_{2}\right)$ with keeping $\mathrm{pH}$ constant is revealed in Figure 4(c). From Figure 4(c), it can be observed 


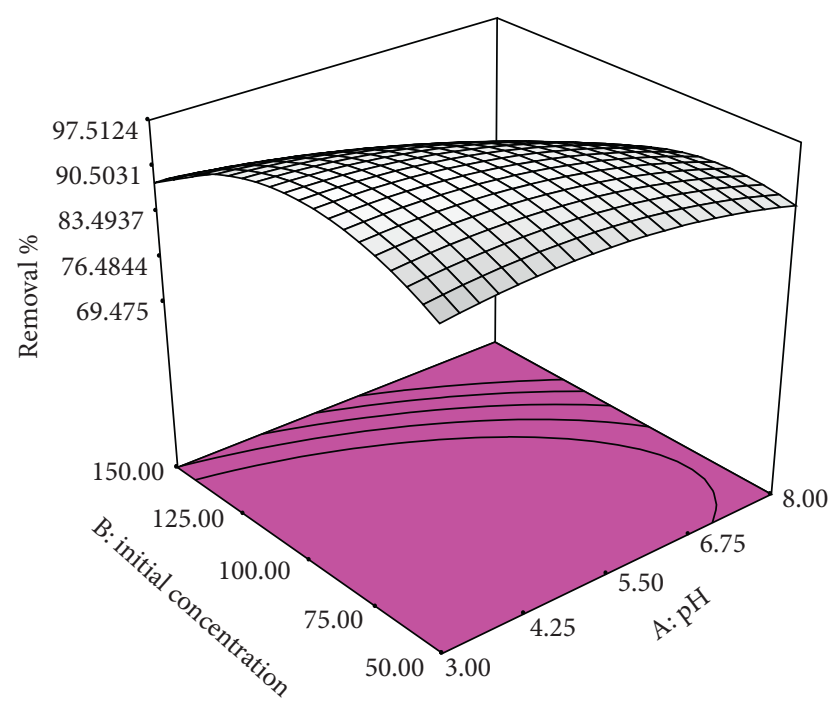

(a)

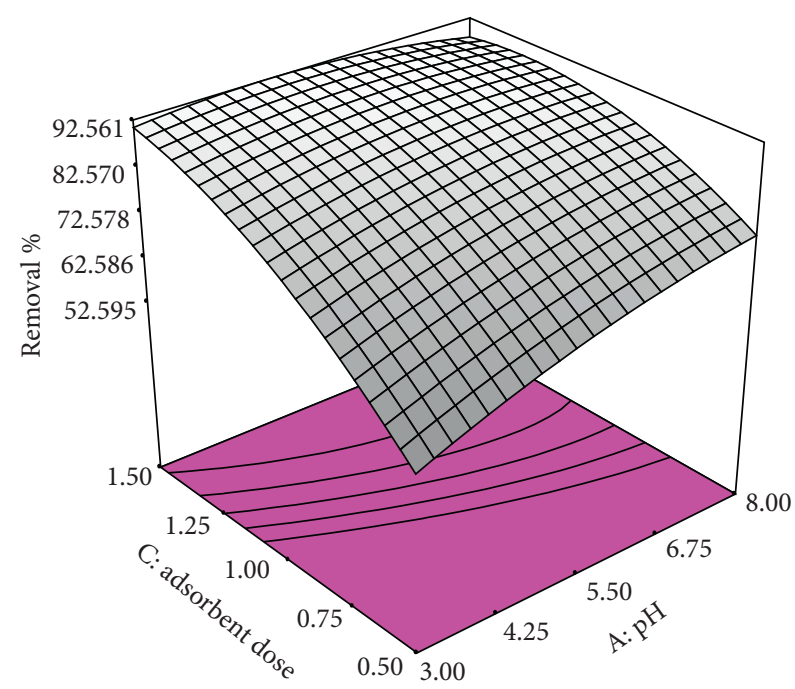

(b)

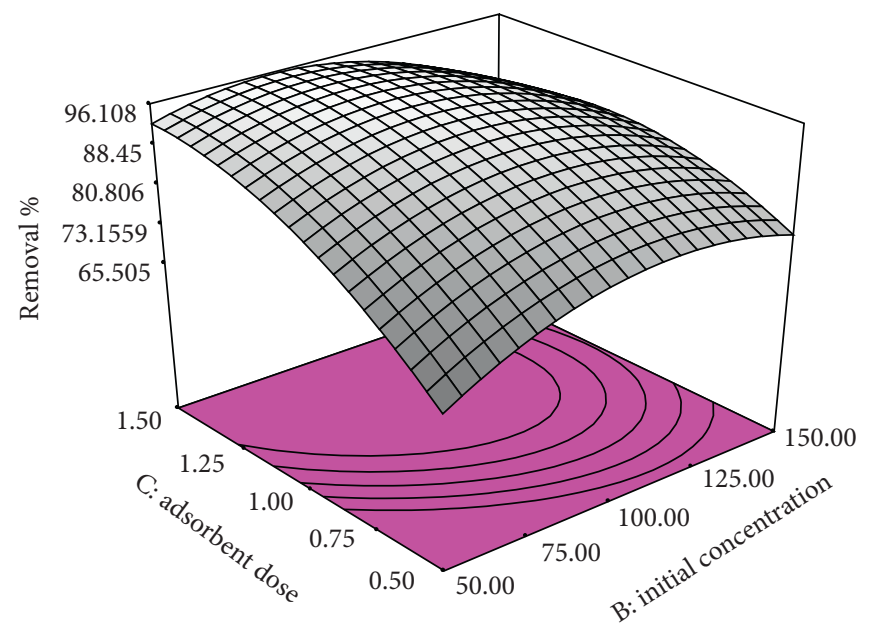

(c)

Figure 4: Surface plots for the effects of (a) the solution of $\mathrm{pH}$ and initial $\mathrm{Pb}$ (II) ion concentration; (b) initial Pb (II) ion concentration and (c) adsorbent dose; and (c) adsorbent dose and initial Pb (II) concentration on the removal (\%).

that the adsorption capacity increased when the adsorbent dose increased from 0.5 to $1.5 \mathrm{~g}$ and the initial $\mathrm{Pb}$ (II) ion concentration decreased from 150 to $50 \mathrm{mg} / \mathrm{L}$. The increase in the adsorbent dose provided a greater surface area or increased available adsorptions sites which increased the amount of $\mathrm{Pb}$ (II) adsorbed.

The optimization process was performed by numerical optimization defined in the Design-Expert software. In numerical optimization, the program seeks to maximize the desirability function to create the optimal condition. All the three factors and $\mathrm{Pb}$ (II) removal efficiency were set in experimental ranges for the maximum desirability. Optimization was done by considering the values of parameters for better removal for $\mathrm{Pb}$ (II) ion from aqueous solution using CISAC, that is, $\mathrm{pH}$ value of 5.5, adsorbent dose of $1.35 \mathrm{~g}$, and initial $\mathrm{Pb}$ (II) ions concentration of $102.37 \mathrm{mg} / \mathrm{L}$ with the desirability of 1 (Figure 5 ). Therefore, using these values, the removal efficiencies of $\mathrm{Pb}$ (II) ion from aqueous solution and paint industry wastewater were found to be
$98 \%$ and $70 \% . \mathrm{Pb}$ (II) ion removal efficiency of CISAC in paint wastewater was much lower than in aqueous solution because paint industry wastewater contained different types of heavy metals $\left(\mathrm{Cu}^{+2}, \mathrm{Cr}^{+3}\right.$, and $\left.\mathrm{Zn}^{+2}\right)$, binders, additives, biological oxygen demand $\left(\mathrm{BOD}_{5}\right)$, chemical oxygen demand (COD), total suspended solids and turbidity that affected the $\mathrm{Pb}$ (II) ion removal efficiency by competing one another in the adsorbent site.

3.7. Adsorption Equilibrium Isotherm Studies. The equilibrium isotherm experiments were carried out using $1.5 \mathrm{~g} /$ $100 \mathrm{ml}$ of Canna indica activated carbon with $\mathrm{pH}$ of 5.5 and the initial $\mathrm{Pb}$ (II) ions concentrations (50, 100, and $150 \mathrm{mg} / \mathrm{L}$ ) under room temperature. The adsorbate-adsorbent solutions were mixed at a constant speed of $250 \mathrm{rpm}$ for an equilibrium time of $120 \mathrm{~min}$. Figures 6(a) and 6(b) represent the Langmuir and Freundlich isotherm adsorption of $\mathrm{Pb}$ (II) ion on CISAC, and Table 5 shows the parameters of these 


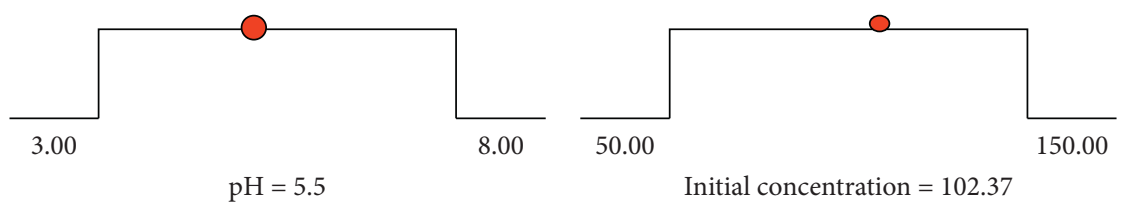

(a)

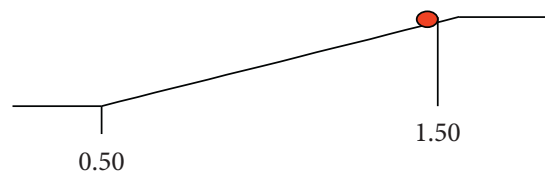

Adsorbent dose $=1.35$

(c)

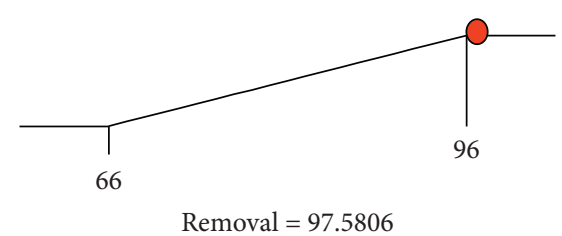

(d)

FIgUre 5: Desirability ramp for numerical optimization of four goals, namely, the solution pH (a), initial Pb (II) ion concentration (b), adsorbent dose (c), and removal efficiency (d).

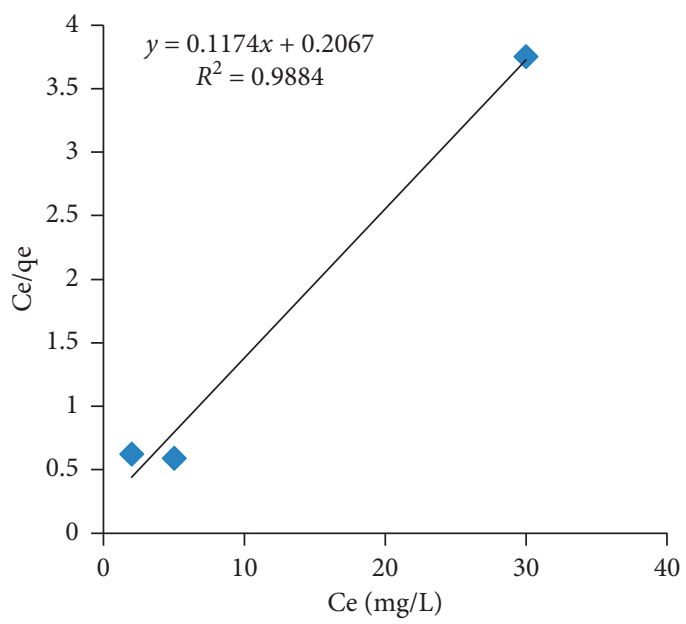

(a)

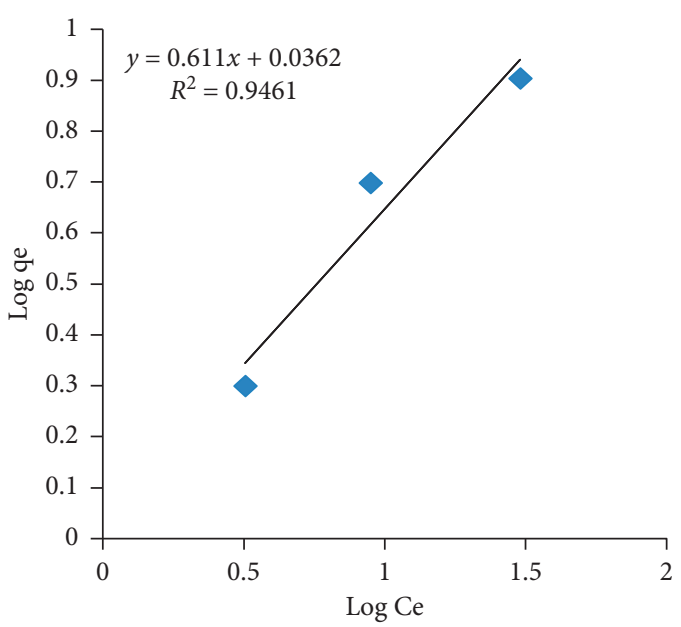

(b)

FIGURE 6: Langmuir plot (a) and Freundlich plot (b) for Pb (II) ion adsorption on CISA.

TABLE 5: The isotherm parameters of Langmuir and Freundlich for $\mathrm{Pb}$ (II) adsorption by CISAC.

\begin{tabular}{lccccrr}
\hline $\begin{array}{l}\text { Langmuir parameters } \\
q_{m}(\mathrm{mg} / \mathrm{g})\end{array}$ & $K_{L}(\mathrm{~L} / \mathrm{mg})$ & $R^{2}$ & $\begin{array}{c}\text { Freundlich parameters } \\
k_{f}(\mathrm{mg} / \mathrm{g})\end{array}$ & $n$ & $1 / n$ & $R^{2}$ \\
\hline 8.52 & 0.57 & 0.9884 & 1.44 & 1.64 & 0.61 \\
\hline
\end{tabular}

isotherms. The correlation coefficients $\left(R^{2}\right)$ of Langmuir and Freundlich isotherms models are 0.9884 and 0.9461 , respectively. Thus, the adsorption of $\mathrm{Pb}$ (II) on CISAC fits the model of Langmuir very well.

\section{Conclusion}

The present study shows that CISAC is a good adsorbent for the removal of $\mathrm{Pb}$ (II) ions from aqueous solution and paint industry wastewater. Better removal (98\%) was achieved at an initial $\mathrm{Pb}$ (II) ion concentration of $102.4 \mathrm{mg} / \mathrm{L}$, an adsorbent dosage of $1.4 \mathrm{~g}$, and $\mathrm{pH}$ of 5.5 . With the same condition, $69.7 \%$ of $\mathrm{Pb}$ (II) ion was removed from the paint industry wastewater. The performance of the CISAC for the removal of $\mathrm{Pb}$ (II) ion in the paint industry wastewater was much lower than in aqueous because the paint industry wastewater contains various types of pollutants. Adsorption isotherm showed that the Langmuir isotherm model provides the best correlation of $R^{2}(0.9884)$. The treated wastewater characteristics were below the standard set by WHO (2017) except for COD and TSS. Hence, further treatment is needed to remove the excess COD and TSS before disposing to the environment. The findings of the current study suggest that the adsorption process using 
CISAC is an environmentally friendly and effective adsorbent for the removal of $\mathrm{Pb}$ (II) ions from aqueous solution and paint industry wastewater. However, it is suggested that CISAC might have the potential to remove other heavy metals, and further studies are recommended for the authentication.

\section{Data Availability}

The information used in this study can be obtained from the corresponding author upon request.

\section{Conflicts of Interest}

The authors have no conflicts of interest.

\section{Acknowledgments}

This study was supported financially by the Ethiopian Road Authority.

\section{References}

[1] J. Ocreto, C. I. Go, J. C. Chua, C. J. Apacible, and A. Vilando, "Competitive effects for the adsorption of copper, cadmium and lead ions using modified activated carbon from bambo," MATEC Web of Conferences, vol. 268, Article ID 6021, 2019.

[2] J. He and J. P. Chen, "A comprehensive review on biosorption of heavy metals by algal biomass: materials, performances, chemistry, and modeling simulation tools," Bioresource Technology, vol. 160, pp. 67-78, 2014.

[3] E. Bernard, A. Jimoh, and J. Odigure, "Heavy metals removal from industrial wastewater by activated carbon prepared from coconut shell," Research Journal of Chemical Sciences, vol. 2231, p. 606x, 2013.

[4] M. Sobh, M. A. Moussawi, W. Rammal et al., "Removal of lead (ii) ions from waste water by using lebanese cymbopogon citratus (lemon grass) stem as adsorbent," American Journal of Phytomedicine and Clinical Therapeutics, vol. 2, pp. 1070-1080, 2014.

[5] A. M. El-wakil, E. M. W. M. Abou, and F. S. Awad, "Removal of lead from aqueous solution on activated carbon and modified activated carbon prepared from dried water hyacinth plant," Journal of Analytical \& Bioanalytical Techniques, vol. 5, pp. 1-14, 2014.

[6] Z.-J. Yi, J. Yao, Y.-F. Kuang, H.-L. Chen, F. Wang, and Z.-M. Yuan, "Removal of pb (ii) by adsorption onto Chinese walnut shell activated carbon," Water Science and Technology, vol. 72, pp. 983-989, 2015.

[7] I. C. Chukwujike, C. Ewulonu, S. C. Nwanonenyi, and I. Uche, "Adsorption treatment of industrial paint effluent for the removal of pollutants by local clays," International Journal of Scientific and Engineering Research, vol. 6, no. 10, pp. 690-703, 2015.

[8] M. Auta and B. H. Hameed, "Preparation of waste tea activated carbon using potassium acetate as an activating agent for adsorption of acid blue 25 dye," Chemical Engineering Journal, vol. 171, no. 2, pp. 502-509, 2011.

[9] O. Ogunleye, O. Adio, and T. Salawudeen, "Removal of lead (ii) from aqueous solution using banana (musa paradisiaca) stalk-based activated carbon," Chemical and Process Engineering Research, vol. 28, pp. 45-59, 2014.

[10] L. Mouni, D. Merabet, A. Bouzaza, and L. Belkhiri, "Adsorption of $\mathrm{Pb}$ (II) from aqueous solutions using activated carbon developed from Apricot stone," Desalination, vol. 276, no. 1-3, pp. 148-153, 2011.

[11] P. V. Thitame and S. R. Shukla, "Removal of lead (ii) from synthetic solution and industry wastewater using almond shell activated carbon," Environmental Progress \& Sustainable Energy, vol. 36, pp. 1628-1633, 2017.

[12] F. Alguacil, 1. Alcaraz, I. García-Díaz, and F. López, "Removal of $\mathrm{pb} 2+$ in wastewater via adsorption onto an activated carbon produced from winemaking waste," Metals, vol. 8, no. 9, p. 697, 2018.

[13] M. Momčilović, M. Purenović, A. Bojić, A. Zarubica, and M. Ranđelović, "Removal of lead (ii) ions from aqueous solutions by adsorption onto pine cone activated carbon," Desalination, vol. 276, pp. 53-59, 2011.

[14] S. Mopoung, P. Moonsri, W. Palas, and S. khumpai, "Characterization and properties of activated carbon prepared from tamarind seeds by koh activation for fe (iii) adsorption from aqueous solution," The Scientific World Journal, vol. 2015, Article ID 415961, 9 pages, 2015.

[15] S. Uwadiae and O. Edokpiawe, "Modelling and optimization of lead adsorption from aqueous solution using groundnut shell," Acta Technica Corvininesis-Bulletin of Engineering, vol. 12, 2019.

[16] O. S. Bello, A. Inyinbor, A. O. Dada, and A. A. Kayode, "Preparation and characterization of modified adsorbents derived from pawpaw (carica papaya) leaf," International Proceedings of Chemical, Biological and Environmental Engineering, vol. 96, pp. 64-70, 2016.

[17] S. M. Anisuzzaman, C. G. Joseph, W. M. A. B. W. Daud, D. Krishnaiah, and H. S. Yee, "Preparation and characterization of activated carbon from typha orientalis leaves," International Journal of Industrial Chemistry, vol. 6, no. 1, pp. 9-21, 2015.

[18] O. O. Ogunleye, M. A. Ajala, and S. E. Agarry, "Evaluation of biosorptive capacity of banana $(<\mathrm{i}>$ Musa paradisiaca $</ \mathrm{i}>)$ stalk for lead (ii) removal from aqueous solution," Journal of Environmental Protection, vol. 5, pp. 1451-1465, 2014.

[19] P. Sugumaran, V. P. Susan, P. Ravichandran, and S. Seshadri, "Production and characterization of activated carbon from banana empty fruit bunch and delonix regia fruit pod," Journal of Sustainable Energy \& Environment, vol. 3, pp. 125-132, 2012.

[20] I. Demiral and C. Şamdan, "Preparation and characterisation of activated carbon from pumpkin seed shell using h3po4," Anadolu University Journal of Science and Technology-A Applied Sciences and Engineering, vol. 17, no. 1, pp. 125-138, 2016.

[21] M. S. Shamsuddin, N. R. N. Yusoff, and M. A. Sulaiman, "Synthesis and characterization of activated carbon produced from kenaf core fiber using $\mathrm{H}_{3} \mathrm{PO}_{4}$ activation," Procedia Chemistry, vol. 19, pp. 558-565, 2016.

[22] O. A. Ekpete, A. C. Marcus, and V. Osi, "Preparation and characterization of activated carbon obtained from plantain (Musa paradisiaca) fruit stem," Journal of Chemistry, vol. 2017, Article ID 8635615, 6 pages, 2017.

[23] B. P. Kumar, K. Shivakamy, L. R. Miranda, and M. Velan, "Preparation of steam activated carbon from rubberwood sawdust (Hevea brasiliensis) and its adsorption kinetics," Journal of Hazardous Materials, vol. 136, no. 3, pp. 922-929, 2006.

[24] I. R. Ilaboya, E. Oti, G. Ekoh, L. Umukoro, and A. Ibiam, "Performance of activated carbon from cassava peels for the treatment of effluent wastewater," Iranica Journal of Energy and Environment, vol. 4, no. 4, pp. 361-370, 2013. 
[25] S. Joshi and B. P. Pokharel, "Preparation and characterization of activated carbon from lapsi (choerospondias axillaris) seed stone by chemical activation with potassium hydroxide," Journal of the Institute of Engineering, vol. 9, pp. 79-88, 2013.

[26] S. Adhikaria, B. Pokharel, V. Gurung, R. M. Shrestha, and R. Rajbhandari, "Preparation and characterization of activated carbon from walnut (jaglansregia) shells by chemical activation with zinc chloride $(\mathrm{ZnCl} 2)$," in Proceedings of the IOE Graduate Conference, Kathmandu, Nepal, December 2019.

[27] J. Chen, L. Zhang, G. Yang, Q. Wang, R. Li, and L. A. Lucia, "Preparation and characterization of activated carbon from hydrochar by phosphoric acid activation and its adsorption performance in prehydrolysis liquor," BioResources, vol. 12, no. 3, pp. 5928-5941, 2017.

[28] X. S. Wang, H. J. Lu, L. Zhu, F. Liu, and J. J. Ren, “Adsorption of lead (ii) ions onto magnetite nanoparticles," Adsorption Science \& Technology, vol. 28, pp. 407-417, 2010.

[29] M. Om Prakash, G. Raghavendra, S. Ojha, and M. Panchal, "Characterization of porous activated carbon prepared from arhar stalks by single step chemical activation method," Materials Today: Proceedings, 2020.

[30] X. Cui, S. Fang, Y. Yao et al., "Potential mechanisms of cadmium removal from aqueous solution by Canna indica derived biochar," Science of the Total Environment, vol. 562, pp. 517-525, 2016.

[31] A. Gundogdu, D. Ozdes, C. Duran, V. N. Bulut, M. Soylak, and H. B. Senturk, "Biosorption of $\mathrm{Pb}$ (II) ions from aqueous solution by pine bark (Pinus brutia Ten.)," Chemical Engineering Journal, vol. 153, no. 1-3, pp. 62-69, 2009.

[32] Y. Li, Q. Du, X. Wang et al., "Removal of lead from aqueous solution by activated carbon prepared from Enteromorpha prolifera by zinc chloride activation," Journal of Hazardous Materials, vol. 183, no. 1-3, pp. 583-589, 2010.

[33] M. A. Khan, A. Alemayehu, R. Duraisamy, and A. K. Berekete, "Removal of lead ion from aqueous solution by bamboo activated carbon," International Journal of Water Research, vol. 5, pp. 33-46, 2015.

[34] M. Sekar, V. Sakthi, and S. Rengaraj, "Kinetics and equilibrium adsorption study of lead (ii) onto activated carbon prepared from coconut shell," Journal of Colloid and Interface Science, vol. 279, pp. 307-313, 2004.

[35] N. Udeh and J. Agunwamba, "Equilibrium and kinetics adsorption of cadmium and lead ions from aqueous solution using bamboo based activated carbon," The International Journal Of Engineering and Science, vol. 6, pp. 17-26, 2017.

[36] I. Ozdemir, M. Sahin, R. Orhan, and M. Erdem, "Preparation and characterization of activated carbon from grape stalk by zinc chloride activation," Fuel Processing Technology, vol. 125, pp. 200-206, 2014. 